\title{
Au doping of CdS polycrystalline films prepared by co-sputtering of CdS-Cd-Au targets
}

\author{
Becerril M. ${ }^{1}$, Silva-López H. and Zelaya-Angel O. \\ Departamento de Física, CINVESTAV-IPN \\ Apdo. Postal 14-740, 07000 México, D.F.
}

Vargas-García J.R.

Departamento de Ingeniería en Metalurgia y Materiales, ESIQIE-IPN

(Recibido: 23 de mayo de 2012; Aceptado: 05 de septiembre de 2012)

\begin{abstract}
$\mathrm{Au}$ doped $\mathrm{CdS}$ polycrystalline films were grown on Corning glass substrates at room temperature by co-sputtering from a $\mathrm{CdS}-\mathrm{Cd}-\mathrm{Au}$ target. Elemental $\mathrm{Cd}$ and $\mathrm{Au}$ were placed onto the $\mathrm{CdS}$ target covering small areas. The electrical, structural, and optical properties were analyzed as a function of $\mathrm{Au}$ content. The Au doped $\mathrm{CdS}$ polycrystalline films showed a $p$ type semiconductor nature. It was found that the electrical resistivity drops and the carrier concentration increases as a consequence of $\mathrm{Au}$ incorporation within the $\mathrm{CdS}$ lattice. In both cases, the changes were of several orders of magnitude.
\end{abstract}

Keywords: Thin films; CdS; Sputtering; X-Ray

\section{Introduction}

Doping is a widely studied phenomenon in semiconductor materials to obtain electron or hole conductivities. The effective doping of a semiconductor material considerably increases its potential applications in the fabrication of optoelectronic devices. Some intrinsic structural defects in these materials, such as grain boundaries; act as carrier trapping centers, limiting the conductivity of the films. On the other hand, the deposition of polycrystalline semiconductor films using sputtering techniques is much more economic than the growth of bulk semiconductor materials or than thin layers deposited by techniques such as molecular beam epitaxy (MBE). Thus, an important reduction in the cost of the devices can be achieved by preparing doped polycrystalline thin films with appropriate quality [1]. Among II-VI semiconductors, CdS polycrystalline thin films represent a potential material for large area electronic devices and solar cells, since CdS has a wide direct band gap $(2.42 \mathrm{eV})$. It has been used as a window material together with several semiconductors such as $\mathrm{CdTe}, \mathrm{Cu}_{2} \mathrm{~S}$ and $\mathrm{CuInSe}_{2}$. Also the interest in $\mathrm{CdS}$ thin films stems from its piezoelectric properties and photoelectrochemical cells [2, 3, 4].

Many techniques have been reported in deposition of $\mathrm{CdS}$ thin films. These include evaporation, sputtering, spray pyrolysis, molecular beam epitaxy technique, photochemical deposition and successive ionic layer adsorption and reaction (SILAR) method [5-12]. In all of these deposition methods there are some problems in the prepared samples, for example, it is difficult to obtain stoichiometric CdS films by evaporation technique and a high substrate temperature is required in spray deposition [13]. Most works on Au-doped CdS have reported mainly luminescence properties with the goal to obtain effective phosphorous [14] to fabricate light emission diodes and electroluminescent displays [15-17]. In this work we report the effect of Au-doping of CdS polycrystalline films grown by co-sputtering using a CdS-Cd-Au target. Our results indicate an effective Au p-type doping of CdS which is important for $\mathrm{CdS} / \mathrm{CdTe}$ solar cells fabrication, since $\mathrm{n}$ type CdTe preparation is easier task than p-type CdTe, in such a way that it becomes possible to prepare $\mathrm{p}-\mathrm{CdS} / \mathrm{n}$ CdTe photovoltaic devices as an alternative of the n$\mathrm{CdS} / \mathrm{p}-\mathrm{CdTe}$ heterostructure.

\section{Sample preparation and experimental details}

Polycrystalline CdS films were grown on 7059 Corning glass substrates at room temperature (RT) in a radio frequency (rf) sputtering system with a water cooled cathode. The rf power employed in the growth process was $20 \mathrm{~W}$ and the distance between the target and substrate was $3.5 \mathrm{~cm}$. The chamber was evacuated to a pressure of $1 \times 10^{-5}$ Torr before the addition of pure Ar gas. The total Ar pressure was kept at 1 mTorr during the film growth. Depositions were performed for $45 \mathrm{~min}$. Extra $\mathrm{Au}$ and $\mathrm{Cd}$ atoms were introduced into the films by co-sputtering. Small pieces of elemental Au (99.999\% pure) and $\mathrm{Cd}$ (99.999\% pure) were placed onto the CdS target $(99.999 \%$ pure), which had an area of $4.92 \mathrm{~cm}^{2}$. This technique has been used in a previous work [18]. The area coverage of the additives was kept at $1-3 \% \mathrm{Au}$ and $2 \% \mathrm{Cd}$ of the total target area. The $\mathrm{Cd}$ on the target was added in order to provide the excess of $\mathrm{Cd}$ needed to prevent $\mathrm{Cd}$ vacancies during the formation of the CdS films. The as-deposited films were annealed in $\mathrm{Ar}$ atmosphere for 1 hour $\left(t_{\text {anneal }}\right)$ at $300{ }^{\circ} \mathrm{C}\left(T_{\text {anneal }}\right)$. Undoped $\mathrm{CdS}$ films without annealing treatment were denoted by $\mathrm{D}_{0}$. Annealed films prepared at 1,2 and $3 \% \mathrm{Au}$ of target area coverage were denoted by $\mathrm{D}_{1}, \mathrm{D}_{2}$ and $\mathrm{D}_{3}$, respectively. At $T_{\text {anneal }}>350{ }^{\circ} \mathrm{C}$ and $t_{\text {anneal }}>1$ hour, the film thickness was sensitively affected. The film 


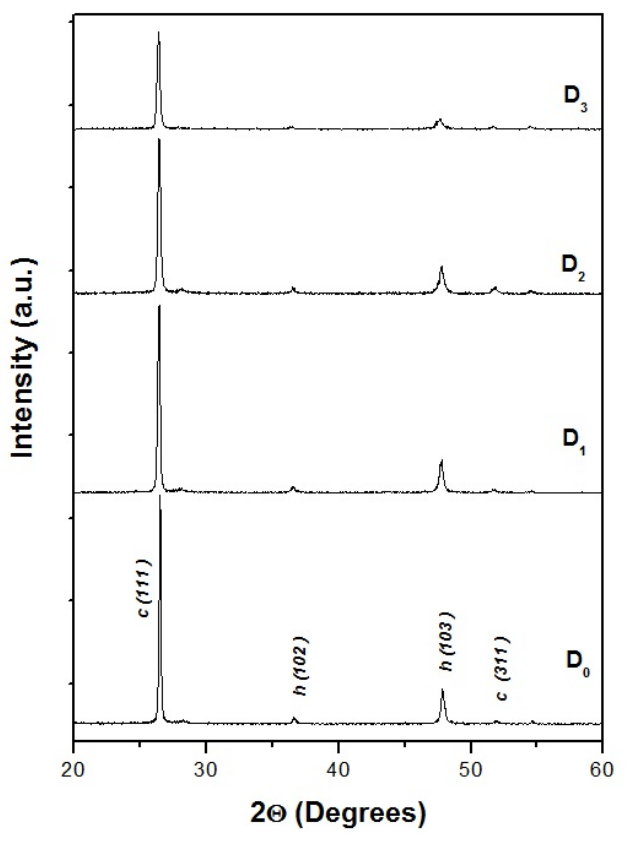

Figure 1. X-ray diffraction patterns of $\mathrm{D}_{0}-\mathrm{D}_{3}$ films. The meaning of $c$ and $h$ on the plane indexes is cubic and hexagonal.

thickness and composition were measured by a KLA TENCOR P-15 Profilometer and an Energy Dispersive Spectroscopy (EDS) system installed in a Field Emission Scanning Electron Microscope (FESEM) JEOL JSM-

$7401 \mathrm{~F}$, respectively. The crystalline structure of the films was determined by X-ray diffraction (XRD) using an X-ray SIEMENS D5000 equipment, with the $\mathrm{CuK \alpha}$ line. Atomic Force Microscopy (AFM) images were obtained with a Microscope Autoprobe CP Research (Veeco Metrology Group). The electrical properties were measured in dark using a 4600 BIO-RAD, DLTS spectrometer. CdS-Au films were heated at $0.30 \mathrm{~K} / \mathrm{s}$ from 100 to $450 \mathrm{~K}$ with an applied bias voltage of $10 \mathrm{~V}$. The dark current signal was measured with a programmable 617 KEITHLEY electrometer connected to a PC. The carrier concentration, mobility and type of conductivity of the films were measured at room temperature using the Van der Pauw method. To perform electrical measurements, high purity Silver Paint electrodes were deposited on CdS films. The I$\mathrm{V}$ plots, in the range 1-50 volts, obtained with this method were linear, indicating ohmic behavior of the contacts in all samples. The optical absorption spectra of the films were measured by a UNICAM 8700 spectrophotometer.

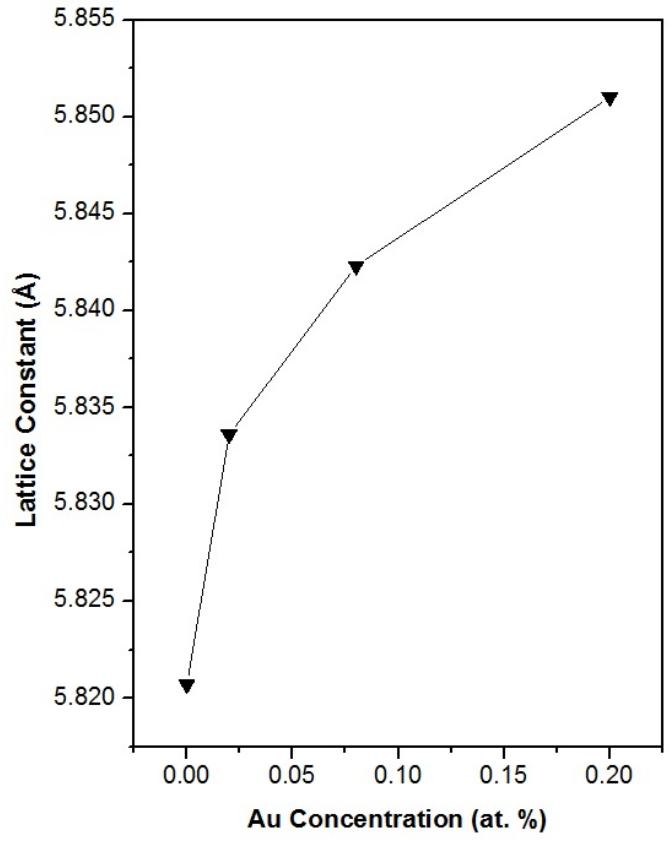

Figure 2. Change of lattice constant of CdS films as a function of $\mathrm{Au}$ content.

Table 1 summarizes the film composition, energy gap $\left(E_{G}\right)$, thermal conductivity activation energy $\left(E_{A}\right)$, mobility, and carrier concentration of the $\mathrm{CdS}$ films at temperature close to RT. It can be observed that Au content increases consistently with the $\mathrm{Au}$ target surface coverage. Fig. 1 shows the X-ray diffraction patterns of the $\mathrm{D}_{0}-\mathrm{D}_{3}$ films. All the diffraction lines in the spectra correspond to a mixture of the cubic and hexagonal phases of CdS with a preferential orientation along the (111) direction. In general, in sputtered films, the mixed structure of hexagonal wurtzite and cubic phase of $\mathrm{CdS}$ is obtained [19]. Besides the c-(111) and c-(311) diffraction lines at $2 \theta=26.36^{\circ}$ and $51.70^{\circ}$, respectively; the characteristic h(102) and $\mathrm{h}-(103)$ lines also appear at $2 \theta=36.66^{\circ}$ and $47.86^{\circ}$, respectively. The pattern corresponding to $\mathrm{D}_{0}$ films shows the most intense diffraction lines, possibly indicating a better crystalline quality. After annealing, the diffraction lines of $\mathrm{D}_{1}-\mathrm{D}_{3}$ films exhibit a slight broadening and a decreasing in their intensity indicating (calculated from the Debye-Scherrer formula) a decrease of the crystalline quality and a reduction in particle size. The analysis of the chemical compositions and X-ray data of

Table 1. Composition, electrical and optical experimental data of the CdS-Au co-sputtered films.

\begin{tabular}{llcccccc}
\hline \multicolumn{1}{c}{ Film } & $\begin{array}{c}\text { Au } \\
(\text { Atom \%) }\end{array}$ & $\begin{array}{c}\mathbf{C d} \\
(\text { Atom \%) }\end{array}$ & $\begin{array}{c}\mathbf{S} \\
(\text { Atom } \\
\%)\end{array}$ & $\begin{array}{c}\mathbf{E}_{\mathbf{G}} \\
(\mathrm{eV})\end{array}$ & $\begin{array}{c}\mathbf{E}_{\mathbf{A}} \\
(\mathrm{eV})\end{array}$ & $\begin{array}{c}\text { Mobility } \\
\left(\mathrm{cm}^{2} \mathrm{~V}^{1} \mathrm{~s}^{-1}\right)\end{array}$ & $\begin{array}{c}\text { Carrier } \\
\left(\mathrm{cm}^{-3}\right)\end{array}$ \\
\hline $\mathbf{D}_{\mathbf{0}}$ (as grown) & 0.0 & 49.12 & 50.88 & 2.44 & -0.46 & --- & --- \\
$\mathbf{D}_{\mathbf{1}}$ & 0.02 & 49.14 & 50.84 & 2.46 & -0.24 & -- & -- \\
$\mathbf{D}_{\mathbf{2}}$ & 0.08 & 49.26 & 50.66 & 2.49 & -0.14 & 7.2 & $p=4.93 \times 10^{16}$ \\
$\mathbf{D}_{\mathbf{3}}$ & 0.20 & 49.37 & 50.43 & 2.52 & -0.12 & 18.4 & $p=2.09 \times 10^{19}$ \\
\hline
\end{tabular}



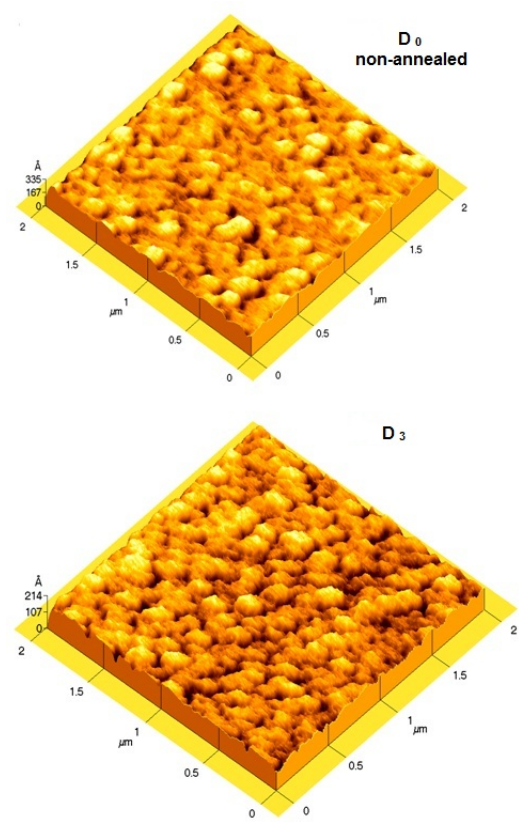

Figure 3. 3D AFM images of non-annealed $D_{0}$ and annealed $D_{3} C d S$ films in Ar atmosphere.

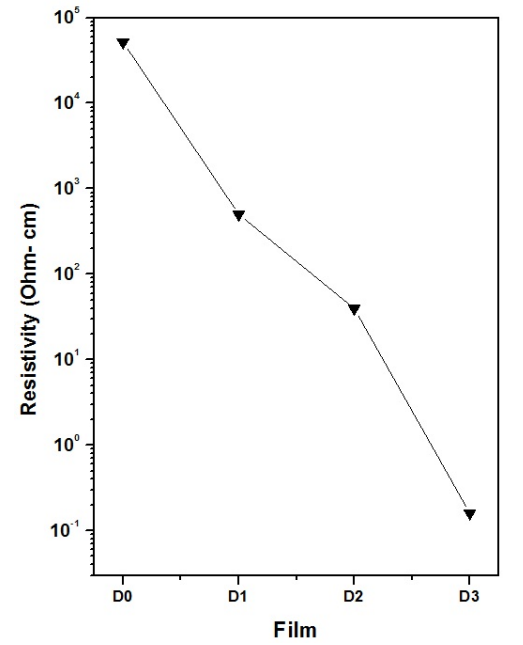

Figure 4. Dark electrical resistivity at RT of the $\mathrm{D}_{0}-\mathrm{D}_{3}$ films.

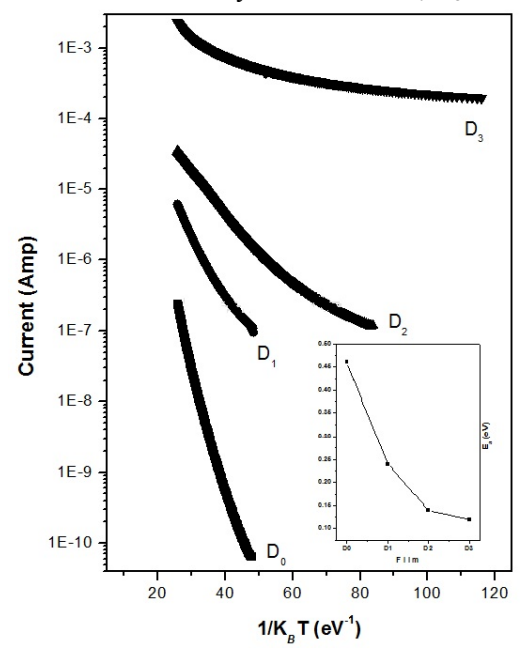

Figure 5. Dark electrical current vs $1 / K_{B} T$ of $D_{0}-D_{3}$ films. The inset exhibits the activation energy $\left(E_{A}\right)$ as a function of the $D_{n}$ films.

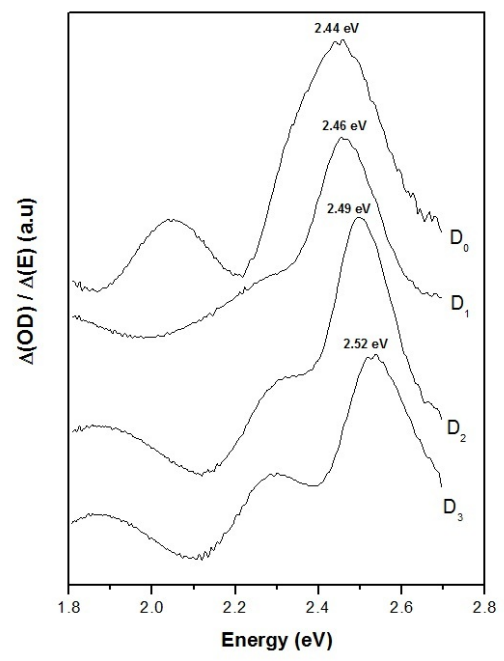

Figure 6. Numerical derivate of the absorption spectra of $\mathrm{D}_{0}-\mathrm{D}_{3}$ films.

$\mathrm{D}_{1}-\mathrm{D}_{3}$ films strongly suggests that $\mathrm{Au}$ atoms could be incorporated into the $\mathrm{Cd}$ sites of the $\mathrm{CdS}$ lattice.

\section{Experimental results and discussion}

The change of lattice constant of CdS films as a function of Au content is shown in Fig. 2. The lattice constant was calculated from the corresponding diffraction pattern using Bragg's law and the most intense peak: c-(111). The undoped CdS films have a lattice constant of $5.820 \AA$. The lattice constant increases with the increase of $\mathrm{Au}$ content. The increase of the lattice constant is indicative of the substitution of $\mathrm{Au}$ for $\mathrm{Cd}$ atoms in the $\mathrm{CdS}$ lattice. The lattice increase can be understood in terms of the difference in atomic size (ionic radii: $\mathrm{Au}^{+}, 1.37 \AA ; \mathrm{Cd}^{2+}, 0.97 \AA ; \mathrm{S}^{2-}$, $1.84 \AA$ ) [20]. Three dimensional $2 \times 2 \mu^{2}$ AFM images of non-annealed $\mathrm{D}_{0}$ and annealed $\mathrm{D}_{3} \mathrm{CdS}$ films in $\mathrm{Ar}$ atmosphere are displayed in Fig. 3. The AFM images reveal no evident change in roughness between annealed and non-annealed films. The non-annealed films present an Rms (root mean square) roughness of $32.9 \AA$, while, despite of the slight increasing of the grain size observed in diffractograms of Fig. 1, the annealed $\mathrm{D}_{3}$ films have Rms roughness of $19.5 \AA$. The change in roughness could be due to the characteristic film growth and heat treatment.

The dark electrical resistivity at RT of CdS films is displayed in Fig. 4. It can be observed that the incorporation of $\mathrm{Au}$ within $\mathrm{CdS}$ lattice produces strong effects in the electrical resistivity. The undoped CdS films $\left(\mathrm{D}_{0}\right)$ were found to be insulating $\left(\rho=5.17 \times 10^{4} \Omega\right.$-cm), which is a typical behavior of polycrystalline $\mathrm{CdS}$ thin films [21]. In contrast, the resistivity of $D_{1}$ and $D_{2}$ films drops two and three orders of magnitude; respectively, compared with that of $\mathrm{D}_{0}$ films. The resistivity of $\mathrm{D}_{3}$ films decreases even by five orders of magnitude. On the other hand, the carrier concentration varies from $10^{16} \mathrm{~cm}^{-3}$ in $\mathrm{D}_{2}$ films to $10^{19} \mathrm{~cm}^{-3}$ in $\mathrm{D}_{3}$ films (see Table 1). The mobility of the electrons, as calculated by the Hall Effect, has a maximum for $\mathrm{D}_{3}$ films of about $18.4 \mathrm{~cm}^{2} \mathrm{~V}^{-1} \mathrm{~s}^{-1}$. These results indicate that $\mathrm{Au}$ is effectively doping the $\mathrm{CdS}$ films. 
In addition, Hall measurements indicate that Au doped $\mathrm{CdS}$ films are $p$-type, since Au most likely acts as acceptor by substituting $\mathrm{Cd}$ atoms [22].The formation of $\mathrm{Cd}$ vacancies $\left(\mathrm{V}_{\mathrm{Cd}}\right)$ is the main defect responsible for doping compensation in $\mathrm{CdS}: \mathrm{Au}$, in our case the co-sputtering of $\mathrm{CdS}-\mathrm{Cd}-\mathrm{Au}$ avoids the formation of a large $\mathrm{V}_{\mathrm{Cd}^{-}}$density, giving as result an effective p-doping of $\mathrm{CdS}$ by the gold atoms, similar to In doped CdTe [23]. In order to compensate the absence of one positive charge in the $\mathrm{Au}^{+}$ ion when it substitutes the $\mathrm{Cd}^{2+}$ a vacancy of $\mathrm{S}^{2-}$ is needed for every-two $\mathrm{Au}^{+}$cations present in the lattice. The effect of temperature on the electrical dark current of CdS films is shown in Fig. 5. All the films present a semiconductor behavior with a thermally activated conductivity in the high temperature region. Undoped CdS films exhibit the typical exponential behavior of an intrinsic semiconductor. The activation energy $\left(\mathrm{E}_{\mathrm{A}}\right)$ for electronic conduction of these films is of about $0.46 \mathrm{eV}$, estimated from the slope of the straight part of the curve, i.e., at temperature closer RT. The incorporation of $\mathrm{Au}$ to the films results in a decrease of the activation energy in the order of $0.24,0.14$ and $0.12 \mathrm{eV}$ for $\mathrm{D}_{1}, \mathrm{D}_{2}$ and $\mathrm{D}_{3}$ films, respectively. In particular, $\mathrm{D}_{1}, \mathrm{D}_{2}$ and $\mathrm{D}_{3}$ films show a significant deviation from the straightline behavior in the low temperature region, which has been generally observed in doped semiconductors. The $\mathrm{E}_{\mathrm{A}}$ is listed in Table 1 and plotted in the inset of Fig. 5.

The band gap energy of the $\mathrm{CdS}$ films was estimated from the film optical density using the derivative method. Typical plots of the optical density derivative as a function of wavelength are shown in Fig. 6. The maximum in the curve gives an approximate value of the energy gap [23].The position of the peak shifts toward higher energy values as $\mathrm{Au}$ content increases in the films. With the increasing of the lattice parameter when the $\mathrm{Au}$ content increases (see Fig. 2) a reduction of the band gap energy is expected, that is, contrary to the result indicated in Fig. 6. The shift of the band gap to higher values could be due to the Moss-Burstein Effect [24].

\section{Conclusions}

In conclusion, in this work we have shown that the $p$-type semiconductor by $\mathrm{Au}$ doping in polycrystalline films can be produced by the co-sputtering from a composed $\mathrm{CdS}-$ $\mathrm{Cd}-\mathrm{Au}$ target. The incorporation of $\mathrm{Au}$ in $\mathrm{CdS}$ films produces changes in their structural, morphological, electrical, and optical properties. Resistivity values up to $1.6 \times 10^{-1}$ U'-cm were obtained, that is five orders of magnitude lower than that of the corresponding undoped sample. The carrier concentration increased by at least three orders of magnitude, with respect to intrinsic $\mathrm{CdS}$ films. The electron mobility is of the order of $18.4 \mathrm{~cm}^{2} \mathrm{~V}^{-1}$ $\mathrm{s}^{-1}$. Doped CdS films exhibited band gap energy of 2.52 $\mathrm{eV}$.

\section{Acknowledgements}

The authors are grateful to M. Guerrero, A. B. Soto and R. J. Fragoso for their helpful technical assistance. This work was financially supported by CONACyT and ICYTDF Mexico through the project SIP/DF/2007/063.

\section{References}

[1] M. Shao, A. Fischer, D. Grecu, U. Jayamaha, E. Bykov, G. Contreras-Puente, R.G. Bohn, A.D. Compaan, Appl. Phys. Lett. 69, 3045 (1996).

[2] L.L. Kazmerski, F.R. White, G.K. Morgan, Appl. Phys. Lett. 29, 268 (1976).

[3] Y.-F. Lin, J. Song, Y. Ding, S.-Y. Lu, Z. L. Wang, Appl. Phys. Lett. 92, 022105 (2008).

[4] T.C. Dang, D.L. Pham, H.L. Nguyen, V.H Pham, Adv. Nat. Sci.: Nanosci. Nanotechnol. 1, 035010 (2010).

[5] P. P. Sahay, R. K. Nath, S. Tewari, Cryst. Res. Technol. 42, 275 (2007).

[6] F. A. Abouelfotouh, R. Lawadi, M. M. Abd-Elnaby, Thin Solid Films, 96, 169 (1982).

[7] A. Ashour, Turk. J. Phys. 27, 551 (2003).

[8] M. A. Eleruja, A. V. Adedeji, S. O. Azi, O. O. Okulaja, O. K. Osuntola, I. A., O. B. Ajayi, J. Matter. Sci. Lett. 14, 1158 (1995).

[9] D. C. Cameron, W. Duncan, W. M. Tsang, Thin Solid Films, 58, 61 (1979).

[10] M. Ichimura, F. Goto, E. Arai, J. Electrochem. Soc. 146, 1028 (1999).

[11] B.R. Sankapal, R.S. Mane, C.D. Lokhande, Mater. Res. Bull. 35, 177 (2000).

[12] H. M. Pathan, C. D. Lokhande, Bull. Mater. Sci. 27, 85 (2004).

[13] B. K. Gupta, O. P. Agnihotri, Phil. Mag. B 37, 631 (1978).

[14] W. W. Anderson, J. T. Mitchell, Appl. Phys. Lett. 12, 334 (1968).

[15] J. Kaur, N.S. Suryanarayana, V. Dubey, J. Chin. Chem. Lett. 22, 709 (2011).

[16] J. W. Stouwdam, R. A. J. Janssen, Adv. Mater. 21, 2916 (2009).

[17] J. Kaur, N.S. Suryanarayana, V. Dubey, Chalcoge. Lett. 7, $329(2010)$

[18] M. Becerril, O. Zelaya-Ángel, R. Ramírez-Bon, F. J. Espinoza-Beltrán, J. González-Hernández, Appl. Phys. Lett. 70, 452 (1997).

[19] M. Byung-Sik, L. Jae-Hyeong, H. Jung, Thin Solid Films 511, 299 (2006).

[20] C. Kittel, Introduction to Solid State Physics, Chapter 3, p. 78, 7th ed. Wiley, New York (1986).

[21] O. de Melo, L. Hernández, O. Zelaya-Angel, R. LozadaMorales, M. Becerril, E. Vasco, Appl.

[22] Phys. Lett. 65 (10), 1278 (1994).

[23] I.D. Desnica-Frankovic, U.V. Desnica, A. Stötzler, M. Deicher, Physica B 273, 887 (1999).

[24] M. Becerril, H. Silva-López, O. Zelaya-Angel, Rev. Mex. Fís. 50, 588 (2004).

[25] A. L. Stroyuk, V. M. Dzhagan, S. Ya. Kuchmii, M. Ya Valakh, D. R. T. Zahn, C. VonBorczyskowski, Theor. Experim. Chem. 43, 297 (2007). 